\title{
A vontade política e a razão pública como condições de legitimidade democrática
}

\author{
Erlon Dias de Sales Santos*
}

\begin{abstract}
Resumo: Este artigo expõe brevemente como o debate sobre a compatibilidade entre os ideais de liberdade e igualdade e os princípios da democracia deliberativa foi tratado na teoria política. 0 texto discute como autores clássicos trataram da questão da legitimidade para em seguida mostrar como autores contemporâneos colocaram esse aspecto no centro da democracia deliberativa, juntamente com a ideia de razão pública. 0 debate está longe de ser concluído, como se pode notar nos questionamentos que autores contemporâneos apresentaram aos pressupostos centrais da teoria deliberativa. Tudo indica que a teoria democrática ainda deverá enfrentar o problema da compatibilidade tanto em termos teóricos como em termos da prática democrática.
\end{abstract}

Palavras-chave: democracia deliberativa, pluralismo, razão pública, igualdade e liberdade.

\section{Introdução}

O individualismo, enquanto traço normativo da modernidade, faz com que as teorias políticas esmerem-se em ajustá-lo dentro de princípios legítimos de democracia. De maneira correlata, a liberdade negativa ${ }^{1}$ é um desafio teórico na medida em que apresenta pressupostos nem sempre compatíveis com governos realmente existentes (igualdade de liberdade, justiça universal, etc.).

Este trabalho se inicia com uma breve análise dessa problemática em alguns autores clássicos, como Rousseau e os utilitaristas, seguindo o roteiro de Bernard Manin e ressaltando a importância da ideia de vontade política neles.

Em seguida, apresenta os principais argumentos e definições dos teóricos da vertente deliberativa, onde a questão central é harmonizar a pluralidade de concepções em sociedades plurais mediante a interação linguística. Habermas é o autor que forma a principal base desse debate, mas aqui nos deteremos mais atentamente a John Rawls, Joshua Cohen e Bernard Manin.

Por fim, o artigo elenca algumas críticas de Jon Elster e Adam Przeworski aos pressupostos da democracia deliberativa e à ideia de razão pública, além da demonstração de Kenneth Arrow da inconsistência de se replicar na coletividade a suposta racionalidade dos indivíduos ao tomar decisões políticas.

\section{0 debate clássico}

Os pensadores clássicos que se detiveram sobre o tema da democracia e da racionalidade dos cidadãos enfrentaram o grande problema de conciliar os ideais de

\footnotetext{
* Graduando em Ciências Sociais - UFPI

1 Isaiah Berlin (1969 [1958]) define liberdade negativa como a área na qual se pode agir sem obstrução de outrem, em que o indivíduo é limitado apenas pela lei. Essa liberdade está presente numa doutrina relativamente moderna, não incompatível com governos autocráticos e considera que a coerção é ruim por definição.
} 
igualdade e liberdade com o pressuposto da legitimidade de um governo democrático. Nesse sentido, Bernard Manin aponta algumas contradições e limitações das formulações teóricas dos autores clássicos da teoria política.

Para os pensadores do liberalismo, de um modo geral, o dever do Estado se reduziria a um princípio universalizável, qual seja, garantir a liberdade para que cada indivíduo possa perseguir seus objetivos. Entretanto, alerta Manin, em sociedades desiguais, algumas pessoas não têm condições materiais de alcançar seus objetivos. A solução seria, então, uma teoria que ampliasse as funções do Estado mínimo sem abrir mão de um caráter racional e universalizante. É o que propõe o princípio da diferença de John Rawls que concebe indivíduos racionais e razoáveis dispostos a aceitar reciprocamente princípios de justiça que tratem desigualmente os indivíduos em condições desfavoráveis a fim de constituir uma sociedade justa.

Só que o pressuposto da unanimidade nesse caso não pode ser colocado, pois alguns indivíduos precisariam adotar o ponto de vista dos menos favorecidos, não o deles próprios. A alternativa para esse dilema é deslocar a exigência da unanimidade das decisões individuais para regras sobre essas decisões, pois as "regras podem ser legítimas apenas quando engendradas pela vontade de todos e representando a vontade de todos" (MANIN, 2007, p. 19). 0 problema subjacente aqui é o de viabilizar a construção de uma ordem política onde as vontades dos indivíduos considerados como iguais possam ser compatíveis com a legitimidade. É desse contexto teórico que surge o princípio da maioria.

0 princípio da maioria é um recurso adotado para manter a unanimidade como fonte da legitimidade. Não é à toa que Emmanuel Joseph Sieyès espera que a maioria conserve os atributos da soma das vontades individuais, pressupondo que a sociedade e o governo existem em função de uma vontade comum e concluindo que a unanimidade é um "objetivo muito difícil de alcançar, mesmo entre um pequeno grupo de pessoas, [e] torna-se impossível em uma sociedade de milhares de indivíduos. [...] Temos de estar satisfeitos com a pluralidade" (SEYÈs apud MANIN, 2007, p. 20) como substituta legítima da unanimidade, desde que a vontade da maioria seja preservada.

Partindo de uma concepção diversa, Rousseau enfrenta esse mesmo problema ao fazer a distinção entre a vontade de todos e a vontade geral. A primeira é uma mera soma de individualidades; a segunda visa o bem comum, é inalienável, indivisível e as discordâncias em relação a ela seriam erros pessoais. Em outras palavras, só ela "pode dirigir as forças do Estado de acordo com a finalidade de sua instituição, que é o bem comum, porque, se a oposição dos interesses particulares tornou necessário o estabelecimento das sociedades, foi o acordo desses mesmos que o possibili- 
tou" (Rousseau, 1978, p. 43).

Dessa forma, quando os cidadãos obedecessem à vontade geral estariam obedecendo a si próprios e sendo livres. Nessa mesma linha, encontra-se Kant, com sua definição de autonomia: "a autonomia da vontade é a qualidade que a vontade tem de ser lei para si mesma, independentemente de uma qualidade qualquer dos objetos do dever" (KANT apud BoBBio, 1995, p. 62).

No entanto, diz Manin, essas teorias não superam as incoerências entre o individualismo moderno e os princípios democráticos. Apenas o utilitarismo teria conseguido justificar o princípio da maioria, utilizando a fórmula max-min, segundo a qual uma lei é legítima quando ela maximiza a felicidade do maior número de indivíduos homogêneos. Mas essa doutrina ainda é falha por desconsiderar as diferenças entre os indivíduos algo incongruente com sociedades plurais.

\section{Pluralismo e razão pública}

O primeiro passo para superar essas limitações é diferenciar a decisão da deliberação e rejeitar o pressuposto de que vontades pré-determinadas de indivíduos são a fonte da legitimidade. A deliberação é, pelo menos em Manin, o processo de formação da vontade, diferente de um momento pontual - o da decisão. Além disso, os indivíduos detêm todo o conhecimento possível da vida social; isso implica que é preciso decidir em condições de incerteza, e é para isso que serve a deliberação.

Como não existe um conjunto de opiniões e conhecimentos definidos a priori entre as pessoas, a deliberação desponta como uma possibilidade de conciliar a liberdade individual e o bem comum ao colocar a deliberação de todos como a fonte da legitimidade. Dessa maneira, é possível dar importância à pluralidade e reconhecer a existência de pontos de vista múltiplos e conflitantes, e assumir que "o direito legítimo consiste no resultado de uma deliberação geral, e não na expressão da vontade geral" (MANIN, 2007, p. 31).

Para a vertente deliberativa, a diversidade de opiniões favorece tanto a liberdade individual, por oferecer maior número de alternativas, quanto a racionalidade do processo. Entretanto, há uma questão essencial sobre a qual não há consenso - a questão da verdade. Para Manin, "as pessoas não precisam ser persuadidas da verdade. Nesse sentido, a argumentação difere da demonstração lógica” (ibidem, p. 33). Por outro lado, para Habermas, os "valores e as normas com os quais as motivações são formadas, têm uma relação imanente com a verdade" (HABERMAS, 1994, p. 121), pois as normas têm um sentido vinculante uma vez que suas pretensões de validade foram aceitas, e os participantes de um debate só chegam a aceitar certas razões quando se convencem de que elas estão, em determinadas circunstâncias, 'certas'. Já 
John Rawls propõe que, no exercício da razão pública, seja realizada a substituição "de doutrinas abrangentes referentes à verdade e ao justo por uma ideia do politicamente razoável endereçado aos cidadãos enquanto cidadãos" (RAWLS, 2007, p. 146). Ainda de acordo com as considerações de Manin, o processo deliberativo possui as seguintes características: ele não é resultado de propostas universais, embora as incentive; se encerra por meio da escolha (voto); o procedimento de confrontação de visões é tão importante para a legitimidade quanto a regra da maioria (princípio de tomada de decisão); faz com que as instituições obriguem a maioria a considerar os pontos de vista minoritários e estabelece que o "verdadeiro objetivo do pluralismo entre forças opostas não é o equilíbrio; é a própria deliberação" (MANIN, 2007, p. 42), evitando, assim, o irrealismo de se exigir a unanimidade.

Contudo, o pluralismo não reduz o processo político baseado na igualdade a um mero conjunto de procedimentos. Joshua Cohen (2007 [1989]) argumenta que a autorização coletiva (requisito para a legitimidade) pode compatibilizar procedimentos com aspectos substantivos por meio da mediação da razão prática, ainda que não exista uma garantia de convergência entre moralidades abrangentes.

Para Cohen, a democracia deliberativa pretende institucionalizar o ideal de que a argumentação pública justifica o exercício do poder, "estabelecendo uma estrutura que lhe assegura a responsividade (responsiveness) e accountability do poder político por meio de eleições competitivas regulares, condições de publicidade, supervisão legislativa [...]" (CoHEN, 2007, p. 122). Isto está próximo do critério de Dahl de que "uma caraterística-chave da democracia é a contínua responsividade do governo às preferências de seus cidadãos, considerados como politicamente iguais" (DAHL, 2012, p. 25).

Para que exista essa argumentação pública, é preciso exigir que as razões colocadas no debate sejam aceitáveis pelos outros, o que estimularia a autonomia política, ou seja, todos são governados por decisões coletivas. Mas isto só seria possível no interior de uma comunidade política atuando sem restrições de concepções morais ou religiosas, pois caso contrário, o pluralismo político seria inviável.

Não obstante a necessidade de aceitação recíproca das opiniões diversas pelos indivíduos, é preciso, ainda, que uma série de 'arranjos sociais e políticos' também justifiquem a deliberação. Para Joshua Cohen, esses arranjos são possíveis mediante a garantia das liberdades dos modernos e a vinculação entre igualdade política e bem comum.

Quanto à ideia de liberdade dos modernos, a concepção deliberativa tende a mostrar que ela não é um fator desagregador da sociedade, se levado em conta o pluralismo razoável e o que Cohen chama de princípio da inclusão deliberativa, isto 
é, uma consideração igual dos interesses aliada a razões politicamente aceitáveis. Aqui, se teria uma condição necessária, mas não suficiente para a democracia. Já em relação ao princípio do bem comum, este "começa pela observação de que os cidadãos têm boas razões para rejeitar um sistema de políticas públicas que falha totalmente ao promover seus interesses" (COHEN, 2007, p. 131). Mas para que esses interesses sejam promovidos sem que se afete a igualdade, é preciso que se estabeleça um mínimo de bem-estar. Para Cohen, a teoria da justiça rawlsiana seria um exemplo disso.

Completando a série de arranjos necessários para a democracia, seria preciso garantir um princípio de participação, algo próximo à liberdade dos antigos. Conforme este princípio, "a escolha coletiva democrática - institucionalizando o vínculo entre justificação deliberativa e o exercício do poder público - deve assegurar direitos de participação iguais [...] e uma exigência mais geral de igualdade de oportunidades para a influência efetiva" (ibidem, p. 132).

Postas essas considerações, cabe agora examinar a ideia de razão pública. Para John Rawls, ela é parte constitutiva de uma sociedade democrática constitucional bem-ordenada, ou seja, parte de uma democracia deliberativa. Para ser compatível com o pluralismo político, qualquer doutrina abrangente não pode se contrapor à democracia. Isso quer dizer que sua "exigência básica consiste em que uma doutrina razoável aceite um regime democrático constitucional e a ideia de um direito legítimo que o acompanha" (RAWLS, 2007, p. 146).

Sua pretensão é articular igualdade e liberdade numa estrutura básica de sociedade cuja virtude primeira é a justiça, que buscará, por sua vez, a cooperação. Para essa sociedade bem ordenada (associação de pessoas que cooperam e tem conflitos) existir, seria necessária uma concepção pública de justiça, onde se busca um consenso sobre valores políticos fundamentais. Isto pressupõe uma reflexividade, isto é, que se relativizem as bases de nossas próprias crenças como se estivéssemos conscientes da contingência de nossos sistemas de valores. Em outras palavras, se afirma um pluralismo que define os seus próprios limites (pluralismo razoável). Isto implica que "a razão pública é a razão da cidadania. É ela que deve guiar o raciocínio dos cidadãos" (Boladeras \& CAMPILlo, 2001, p. 217).

Essa concepção de justiça e de razão pública seria estritamente política e modular, em vez de religiosa, moral ou metafísica; porque desse modo seria eficaz para resolver conflitos da vida social provenientes de doutrinas abrangentes, pois seria independente das dimensões que causam esses conflitos. Essa eficácia não se refere às resoluções práticas das disputas controversas, mas, de outro modo, à especificação dos termos em que se decidirá politicamente. Seu aspecto público provém de 
sua natureza e conteúdo públicos, além de servir como razão para os cidadãos em questões de justiça. As doutrinas abrangentes não se restringiriam, contudo, à esfera privada; elas teriam um caráter público na medida em que fossem razoáveis, que servissem efetivamente de apoio ao consenso sobreposto e que fossem traduzíveis em valores políticos aceitáveis por todos os cidadãos.

O liberalismo político de Rawls já dá como existente a realidade de um pluralismo razoável e não-caótico. A aparente incompatibilidade entra as concepções de bem seria resultado mais de tentativas incoerentes de sincronizá-las ou sobrepô-las do que a alguma ininteligibilidade entre elas. Mas não pressupõe, entretanto, que a sociedade possa ser imediatamente considerada uma comunidade política coesa. Ao contrário,

A pluralidade de pessoas e suas comunidades culturais chega a configurar uma unidade política na medida em que converge no consenso sobreposto que expressa a extensão da identidade pessoal e cultural à cultura política básica da sociedade, que se objetiva no consenso constitucional do estado democrático. [...] Por outro lado, para que o pluralismo exista, a mesma estrutura básica da sociedade deve prover o caminho inverso que facilite a vigência ativa e livre da dimensão cultural dos direitos humanos fundamentais antes designados (ForNARI, 2003, p. 10).

A ideia de razão pública tem a função de especificar o lugar dos valores morais e políticos na relação entre governo e cidadãos, definindo as questões políticas fundamentais, as pessoas às quais se aplica, os conteúdos - que são extraídos de concepções razoáveis de justiça -, sua aplicação nas discussões e satisfazendo o critério de reciprocidade. Sua aplicação não se dá em qualquer discussão, mas, outrossim, no fórum político público, que abrange, de modo diverso, os discursos dos juízes, dos representantes do governo, dos candidatos a cargos públicos e do público em geral.

A razão pública é uma condição de legitimidade e "resume as condições de justificação que deve conter todo discurso que pretenda validez política" (VALLEJo, 2012, p. 619) quando os cidadãos razoáveis se concebem como legisladores, admitindo a prescrição da opinião da maioria como direito legítimo. Essa definição deve, porém, dizer o que é considerar um cidadão razoável. A isso Rawls responde:

quando, vendo uns aos outros como livres e iguais num sistema de cooperação social durante gerações, estão preparados para oferecer uns aos outros termos equitativos de cooperação de acordo com o que consideram a concepção mais razoável de justiça política; e quando concordam em agir naqueles termos, mesmo ao custo de seus próprios interesses em situações particulares, desde que outros cidadãos aceitem aqueles termos (RAWLS, 2007, p. 150).

Rawls considera a democracia deliberativa crucial, já que é intrínseca ao pro- 
cesso de argumentação nos assuntos essenciais de justiça, sendo fundamental que os cidadãos conheçam-na e desejem segui-la na sua conduta política, dentro de um quadro de instituições democráticas especificadoras do corpo legislativo.

Essas características dizem respeito mais especificamente à forma da razão pública. Seu conteúdo, por outro lado, é fornecido por uma pluralidade de concepções de justiça, o que significa dizer que o liberalismo político não pode tentar fixá -la em favor de uma única concepção. Rawls chama a atenção para o fato de que a razão pública não se confunde com razão secular porque os princípios da primeira se aplicam às instituições políticas e sociais básicas, podem se apoiar num consenso sobreposto às doutrinas particulares e "podem ser testadas a partir de ideias fundamentais consideradas implícitas na cultura política pública de um regime constitucional" (ibidem, p. 157).

Ademais dessas formulações, o pluralismo pode ser considerado numa dimensão diferente, a exemplo de Robert Dahl, que o aplica ao caso das organizações e, analogamente, aos indivíduos. Para Dahl, uma democracia pluralista (em sentido poliárquico, e não no sentido ideal) é definida pela existência de organizações importantes relativamente autônomas e do dilema entre controle e autonomia, onde os dois são complementares. Esse dilema, comum a todas as democracias, se deve ao fato de que as organizações independentes são frequentemente desejáveis e, ao mesmo tempo podem causar danos ao corpo de cidadãos, ao demos.

São desejáveis porque devem funcionar para impedir a dominação e para ajudar a criar um controle mútuo entre elas e entre os indivíduos. Já a possibilidade de danos é oriunda dos defeitos que elas podem adquirir. Elas podem, segundo Dahl, ajudar a manter a injustiça, quando os seus recursos se convertem em vantagens aos seus líderes e quando se acomodam em relação aos conflitos; podem deformar a consciência cívica ao produzir crenças e percepções fragmentárias nos atores políticos; podem distorcer a agenda pública quando são capazes de alterar os processos de tomada de decisão e alterar o controle final sobre a agenda pública.

\section{Problemas conceituais}

Se existe uma gama de autores que buscam fundamentar uma teoria política baseada no debate público e não na agregação de interesses, também não lhe faltam críticos. Jon Elster tem uma série de objeções relacionadas ao comportamento humano necessário para essa visão, pois é notavelmente difícil que todas as preferências sejam formadas visando o bem público e não os interesses egoístas.

De início, seguindo o argumento de Elster, pode-se questionar um possível paternalismo da teoria deliberativa ao considerar a participação na discussão pú- 
blica uma obrigação. Isso poderia violar a liberdade individual da qual não se quer abrir mão. Outra dificuldade é o pressuposto de que as discussões sempre levariam a um acordo racional unânime, pois para isso não poderia existir uma diferença irreconciliável de opiniões legítimas acerca do bem comum. Além disso, ressalta Elster, "a transformação de preferências não pode fazer mais do que complementar a agregação de preferências, nunca substituí-la completamente" (ELSTER, 2007, p. 235).

Não obstante, a discussão não poderia ser um fim em si mesma, pois ela pode ser mais prejudicial que a ausência de debate, caso parte significativa das pessoas não se alinhem ao ideal do bem comum ou o façam apenas parcialmente. Mas mesmo que todos os indivíduos estivessem alinhados, ainda caberia questionar se o corpo político é melhor do que a soma de suas partes, como pressupõe a democracia deliberativa. A racionalidade das crenças pode ser afetada negativamente na interação, e não apenas construtivamente como supõem os deliberativistas. E se isso acontecer, “os erros randômicos de preferências privadas egoístas podem, em alguma medida, cancelar-se mutuamente e serem menos temidos do que os erros massivos e coordenados, que podem surgir pelo pensamento de grupo" (ibidem, p. 237).

Outra objeção pode ser feita às situações em que a unanimidade for alcançada, pois ela pode ser resultado de um conformismo, em vez de um acordo racional. A ausência de minoria pode ser um indicador de baixa qualidade da democracia, pois na concepção moderna de liberdade "uma pessoa é mais livre quanto mais desejar fazer coisas que não está livre para fazer, pois estas mostram que seus desejos não são, em geral, formados pela adaptação a suas possibilidades" (ibidem, p. 238).

Por fim, Elster objeta que a oposição entre interesse geral e interesse particular é demasiado simplista, pois além de benefícios privados poderem implicar uma concepção de bem comum, não há garantia de que um indivíduo em uma situação ideal de fala remova os desejos egoístas dos argumentos.

Outra crítica à teoria da democracia deliberativa encontra-se em Adam Przeworski. Ele argumenta que a desconsideração à possibilidade de dominação ideológica pode ocultar as patologias da deliberação. A deliberação pode levar pessoas a sustentarem crenças que não são de seu interesse, caso exista um argumento capaz de fazê-lo. Segundo o autor, não é difícil constatar a existência de tais argumentos na sociedade.

Diante disso, a deliberação, segundo seus formuladores, possibilita a emergência de concepções de bem comum numa sociedade plural quanto a valores e crenças. "Mas" - critica Przeworski - "e aqui coloco uma constatação empírica, se é disto que trata a deliberação, então raramente deliberamos. A maior parte da discussão política refere-se não a objetivos, mas aos meios" (PRZEWoRSKI, 2007, p. 280). 
Existe uma crítica de outra ordem, dentro do que ficou conhecido como Teoria da Escolha Social, que não é dirigida diretamente a nenhum autor em específico, mas trata, sem embargo, da relação entre decisões tomadas por indivíduos e por grupos sociais; sobre a possibilidade de preferências coletivas expressarem racionalmente as preferências individuais, isto é, sobre a possibilidade da maioria e/ou da pluralidade constituírem uma função de bem-estar social.

Kenneth Arrow (1963) demonstra, matematicamente, a impossibilidade de isto ocorrer, pelo menos quando se tem em jogo mais de duas alternativas. 0 pressuposto é de que as escolhas racionais são, necessariamente, completas (sempre são capazes de dizer qual alternativa preferem ou se são indiferentes a elas) e transitivas (tem uma relação de preferência para todo o conjunto). Dados esses requisitos, as escolhas devem, ainda, satisfazer a quatro axiomas ou condições: independência das alternativas irrelevantes (quando as ordenações de preferências dependem delas próprias); unanimidade (ou princípio de Pareto); domínio irrestrito, isto é, a função é definida para qualquer conjunto de preferências; e não ser ditatorial, ou seja, quando os perfis de preferências não são determinados por um único indivíduo.

Arrow demonstra que se a racionalidade individual for entendida dessa forma, e se excluídas as possibilidades de comparações interpessoais de utilidade, nunca se pode satisfazer às quatro condições. Mais do que isso, ela só pode ser expressa de forma coletiva quando ditatorialmente. Sua conclusão é de que "se os valores individuais podem ser representados por amplas ordenações particulares, a doutrina da soberania popular [voters] é incompatível com uma racionalidade coletiva" (ARrow, 1963, p. 60).

Isso resulta num desafio para as teorias da democracia e da legitimidade, que é sintetizado no dilema do prisioneiro: "[...] embora a ação mais vantajosa para todos seja a cooperação, não existem incentivos 'racionais' para tal, sendo que o resultado conjunto das ações individuais é socialmente pior para todos os envolvidos" (ANDREWS, 2004, p. 79).

\section{Conclusão}

Ante a esses debates, notamos que a dificuldade de se vincular princípios democráticos a ideais individualistas é recorrente na teoria política. Cada teoria se apresenta como um avanço, mas nenhuma pode pretender esgotar o debate ou mesmo responder definitivamente a questões essenciais. É o que acontece, também, com a definição de democracia deliberativa, que reacendeu o debate sobre a importância da legitimidade para os fundamentos do processo político e de sua substancialidade.

Nunca é demais notar a influência recíproca entre ideias e práticas políticas. 
A continuidade dos debates entre deliberativistas e individualistas não será pautada apenas pelas questões conceituais, mas também pela conjuntura política de um mundo que enfrenta, na prática, os dilemas da deliberação democrática em contextos marcados pela desigualdade, pluralidade de visões de mundo e por doutrinas incompatíveis com a democracia.

De um lado, leis e constituições resguardam direitos individuais sob a influência em autores liberais, de outro, políticas públicas encontram sua justificativa nos princípios de justiça rawlsianos e nas ideias da participação inspiradas na obra de Habermas. Paralelamente, os teóricos políticos direcionam seus esforços para compreender os impactos e mudanças causados por esses princípios. Por meio das demandas da realidade política e das reflexões teóricas, o debate se mantém em movimento.

\section{Referências Bibliográficas}

ANDREWS, C. W. (2004). A teoria da escolha pública e as reformas do Estado: uma crítica habermasiana. São Paulo, Leviathan, n. 1, p. 73-98.

Arrow, K. 1963[1951]. Social choice and individual values. New Haven, Yale University Press.

BERLIN, I.1969 [1958]. Four essays on liberty. New York, Oxford University Press.

Bobbio, N. (1995). Direito e Estado no pensamento de Emanuel Kant. Brasília, ed. UNB. 3 ed.

Boladeras, M.; CAMPILlo, N. (2001). Filosofía social. Madrid, Editorial sínteses.

CoHen, J. (2007). "Procedimento e substância na democracia deliberativa”. In: Werle, D.L.; Melo, R.S. Democracia deliberativa. São Paulo, Esfera pública.

DAHL, R.(2012). Poliarquia: participação e oposição. São Paulo, Edusp, . (1991). Los dilemas del pluralismo democrático: autonomia versus control. México, D.F., Alianza Editorial.

ELSTER, J. (2007). “O mercado e o fórum: três variações na teoria política”. In: WERLE, D.L.; MELo, R.S. Democracia deliberativa. São Paulo, Esfera pública.

ForNARI, A. (2003). “Razonabilidad política y razón cultural. Proyección crítica de la idea de razón pública en John Rawls". Tópicos: Revista de Filosofia de Santa Fé., n. 11. p. 83-97. 
Habermas, J. (1994). A crise de legitimação no capitalismo tardio. Rio de Janeiro, Tempo brasileiro. 2 ed.

MANin, B. (2007). "Legitimidade e deliberação política”. In: WERLE, D.L.; MELO, R.S. Democracia deliberativa. São Paulo, Esfera pública.

PrZEWorSKI, A. (2007). "Deliberação e dominação ideológica”. In: WERLE, D.L.; MELO, R.S. Democracia deliberativa. São Paulo, Esfera pública.

RAWLS, J. (2007). “A ideia de razão pública revisitada”. In: WERLE, D.L.; MELO, R.S. Democracia deliberativa. São Paulo, Esfera pública.

RousSEAU, J.-J. (1978). “O contrato social”. In: Os pensadores. São Paulo, Abril Cultural.

VALLEJO, I. (2012). Argumentos filosóficos, creencias religiosasy razón pública. Anuario F.. n. $45 / 3$ p. $615-644$.

Recebido em agosto/2014

Aprovado em maio/2015 